\title{
Correction: Polymorphisms at phase I-metabolizing enzyme and hormone receptor loci influence the response to anti-TNF therapy in rheumatoid arthritis patients
}

\author{
Luz M. Canet ${ }^{1} \cdot$ Jose M. Sánchez-Maldonado ${ }^{1} \cdot$ Rafael Cáliz $^{1,2} \cdot$ Ana Rodríguez-Ramos $^{1} \cdot$ Carmen B. Lupiañez $^{1}$. \\ Helena Canhão ${ }^{3}$ Manuel Martínez-Bueno ${ }^{4}$ - Alejandro Escudero ${ }^{5}$ - Juana Segura-Catena ${ }^{1} \cdot$ Signe B. Sorensen ${ }^{6,7}$. \\ Merete L. Hetland ${ }^{6,7} \cdot$ María José Soto-Pino $^{2} \cdot$ Miguel A. Ferrer $^{2} \cdot$ Antonio García $^{2}$ - Bente Glintborg ${ }^{6,8}$. \\ lleana Filipescu ${ }^{9}$ Eva Pérez-Pampin ${ }^{10}$ - Alfonso González-Utrilla ${ }^{2}$ Miguel Ángel López Nevot ${ }^{11}$. \\ Pablo Conesa-Zamora ${ }^{12}$ - Alfons den Broeder ${ }^{13}$. Salvatore De Vita ${ }^{14}$. Sven Erik Hobe Jacobsen ${ }^{6,7}$. \\ Eduardo Collantes-Estevez ${ }^{5}$. Luca Quartuccio ${ }^{14} \cdot$ Federico Canzian $^{15} \cdot$ João E. Fonseca ${ }^{16,17} \cdot$ Marieke J. H. Coenen $^{13}$. \\ Vibeke Andersen ${ }^{18,19} \cdot$ Juan Sainz $\mathbb{( D}^{1,2}$
}

Published online: 14 February 2019

(c) Springer Nature Limited 2019

\section{Correction to: The Pharmacogenomics Journal;} https://doi.org/10.1038/s41397-018-0057-x; published online Feb 2019

Juan Sainz

juan.sainz@genyo.es

1 Genomic Oncology Area, GENYO Centre for Genomics and Oncological Research, Pfizer / University of Granada / Andalusian Regional Government, PTS Granada, Granada, Spain

2 Rheumatology Department, Virgen de las Nieves University Hospital, Granada, Spain

3 CEDOC, EpiDoC Unit, NOVA Medical School and National School of Public Health, Universidade Nova de Lisboa, Lisbon, Portugal

4 Area of Genomic Medicine, GENYO Centre for Genomics and Oncological Research, Pfizer / University of Granada / Andalusian Regional Government, Granada, Spain

5 Rheumatology Department, Reina Sofía Hospital/IMIBIC/ University of Córdoba, Córdoba, Spain

6 The Danish Rheumatologic Biobank, the DANBIO Registry and Copenhagen Center for Arthritis Research (COPECARE), Center for Rheumatology and Spine Diseases, Centre of Head and Orthopaedics, Rigshospitalet, Glostrup, Denmark

7 Faculty of Health and Medical Sciences, Department of Clinical Medicine, University of Copenhagen, Copenhagen, Denmark

8 Department of Rheumatology, Gentofte and Herlev Hospital, Copenhagen University Hospital, Copenhagen, Denmark

9 Rheumatology Department, University of Medicine and Pharmacy
The original version of this Article contained an error in the spelling of the author Ana Rodríguez-Ramos, which was incorrectly given as Ana Rodríguez Ramos. This has now been corrected in both the PDF and HTML versions of the Article.

"Iuliu Hatieganu”, Cluj-Napoca, Romania

10 Rheumatology Unit, University Hospital of Santiago de Compostela, Santiago de Compostela, Spain

11 Immunology Department, Virgen de las Nieves University Hospital, Granada, Spain

12 Clinical Analysis Department, Santa Lucía University Hospital, Cartagena, Spain

13 Department of Human Genetics, Radboud University Medical Center, Radboud Institute for Health Sciences, Nijmegen, The Netherlands

14 Department of Medical and Biological Sciences, Clinic of Rheumatology, University of Udine, Udine, Italy

15 Genomic Epidemiology Group, German Cancer Research Center (DKFZ), Heidelberg, Germany

16 Rheumatology and Metabolic Bone Diseases Department, Hospital de Santa Maria, CHLN, Lisbon, Portugal

17 Rheumatology Research Unit, Faculty of Medicine, Instituto de Medicina Molecular, University of Lisbon, Lisbon Academic Medical Center, Lisbon, Portugal

18 Focused Research Unit for Molecular Diagnostic and Clinical Research, IRS-Center Sonderjylland, Hospital of Southern Jutland, DK-6200 Aabenraa, Denmark

19 Faculty of Health Sciences, Institute of Molecular Medicine, University of Southern Denmark, Odense, Denmark 